\title{
Nasolabial cysts - a rare case
}

\author{
A F Bezuidenhout, ${ }^{1} \mathrm{MB} C \mathrm{ChB} ; \mathbf{N}$ S Stofberg, ${ }^{2} \mathrm{MB} C \mathrm{ChB}$ \\ ${ }^{1}$ Department of Diagnostic Radiology, Stellenbosch University, Parow, Cape Town, South Africa \\ ${ }^{2}$ Department of Otorhinolaryngology, Stellenbosch University, Parow, Cape Town, South Africa
}

Corresponding author: A F Bezuidenhout (fouriebez@yahoo.com)

\begin{abstract}
Nasolabial cysts are benign, slow-growing cysts occurring in the nasolabial folds below the alae nasi. We report on a rare case of bilateral nasolabial cysts, of which only 30 cases have been described previously.
\end{abstract}

\author{
S Afr J Rad 2013;17(3):113-114. DOI:10.7196/SAJR.846
}

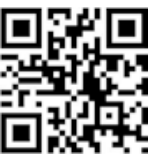

Nasolabial cysts are benign, slow-growing cysts occurring in the nasolabial folds below the alae nasi. ${ }^{[1]}$ These developmental cysts are nonodontogenic, extraosseous and locally expansile. ${ }^{[2]}$ After initial description by Zukerkandl in 1882, approximately 300 cases have been reported in the English literature, with only an estimated $10 \%$ occurring bilaterally. ${ }^{[3]}$ The topographical term 'naso-labial' was initially coined by Rao in 1955 and is the preferred term as the cyst does not originate from the alveolus. ${ }^{[1,4]}$ Synonyms include Klestadt's cyst, nasal vestibule cyst, nasal wing cyst and nasoalveolar cyst. We report on a rare case of bilateral nasolabial cysts, of which only 30 cases have been described previously.

\section{Case report}

A 48-year-old woman presented with a 3-year history of painless, bilateral, infranasal swellings that caused limited anterior nasal blocking. The right-sided mass had previously ruptured into the right nostril, draining a seromucoid material. As plain film does not show the full extent of these lesions, and does not obviate the utility of computed tomogrpahy (CT) scanning, plain film radiography was not performed. CT showed bilateral, well demarcated, ovoid soft tissue lesions anterior to the premaxilla (Fig. 1). There was subtle smooth remodeling of the adjacent maxilla (Fig. 2). No inferior turbinate involvement or nasolacrimal duct extension was present.

Management took the form of surgical excision via a sublabial incision (Fig. 3). Histological sections revealed fibrocollagenous cyst walls bilaterally, lined by pseudostratified ciliated columnar epithelium with areas of squamous metaplasia.

\section{Discussion}

Nasolabial cysts comprise approximately $0.6 \%$ of all jaw cysts. They most commonly affect patients in the 4 th and 5 th decades of life, and have a female predominance of 3.7:1. The presentation is usually that of localised painless swelling, sometimes associated with numbness and loosening of incisor teeth. Slow growth and development of symptoms over months to years is typical. Spontaneous rupture into the nose or oral cavity may occur. Pain may be a feature during secondary infection. Malignant transformation is rare, documented in only one case. ${ }^{[5]}$

The favoured aetiological theory, posited by Bruggeman in 1920, suggests an origin from the remnant of the embryonic nasolacrimal duct, and is is supported by the fact that both the nasolacrimal duct and nasolabial cysts are lined by the same pseudostratified columnar epithelium, and also by the fact that the cyst is located subjacent to the wing of the nose, in line with the naso-optic fissure. ${ }^{[3]}$

The differential diagnosis includes nasolacrimal duct cysts, periapical cysts and dermoid or epidermoid cysts of the oral cavity.

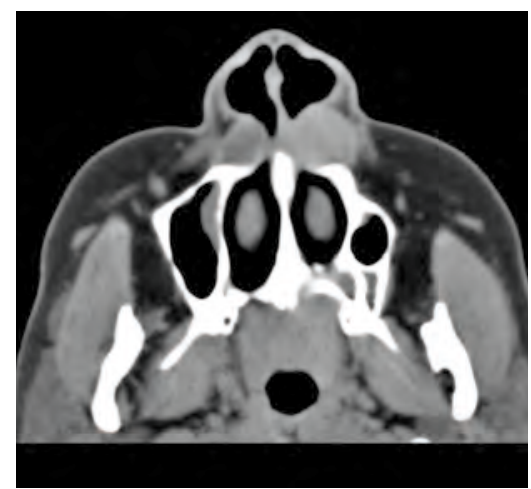

Fig. 1. Bilateral well-demarcated ovoid lesions of soft tissue density anterior to the premaxilla.

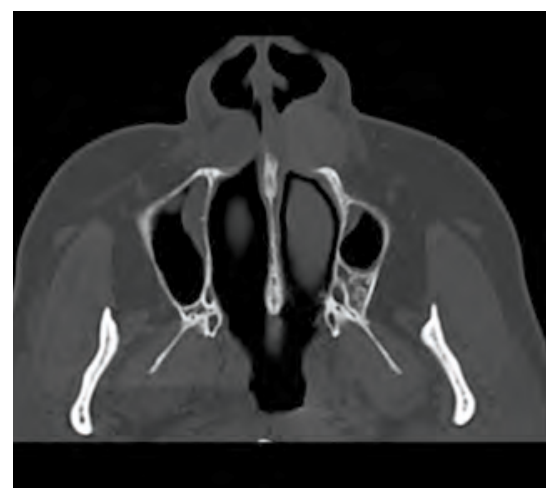

Fig. 2. Subtle smooth remodeling of the adjacent premaxilla and no inferior turbinate involvement.

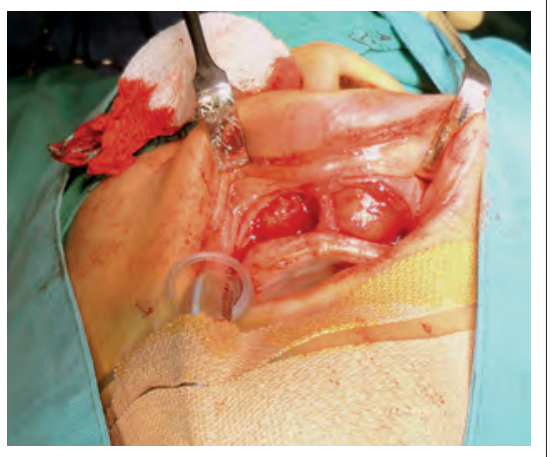

Fig. 3. Surgical approach via a sublabial incision demonstrates the bilateral soft tissue nasolabial cysts. 


\section{PICTORIAL INTERLUDE}

Treatment usually comprises in toto surgical enucleation via a sublabial incision, although open and edoscopic transnasal approaches have been described.$^{[6]}$

1. Shear M, Speight P. Cysts of the Oral and Maxillofacial Regions. 4th ed. Oxford, UK: Blackwell Munksgaard, 2007:119-122.

2. Toribio $\mathrm{Y}$, Roehrl MH. The nasolabial cyst: A nonodontogenic oral cyst related to nasolacrimal duct epithelium. Arch Pathol Lab Med 2011;135(11):1499-1503. [http://dx.doi.org/10.5858/arpa.2010-0338-RS]
3. Patil K, Mahima VG, Divya A. Klestadt's cyst: A rarity. Indian J Dent Res 2007;18:23-26. [http:// dx.doi.org/10.4103/0970-9290.30918]

4. Rao RV. Naso-labial cyst. J Laryngol Otol 1955;69:352-355.

5. Lopez-Rios F, Lassaletta-Atienza L, Domingo-Carrasco C, Martinez-Tello FJ. Nasolabial cyst: Report of a case with extensive apocrine change. Oral Surg Oral Med Oral Pathol Oral Radiol Endod 1997;84:404-406.

6. Chao WC, Huang CC, Chang PH, Chen YL, Chen CW, Lee TJ. Management of nasolabial cysts by transnasal endoscopic marsupialization. Arch Otolaryngol Head Neck Surg 2009;135(9):932-935. [http://dx.doi.org/10.1001/archoto.2009.111. 